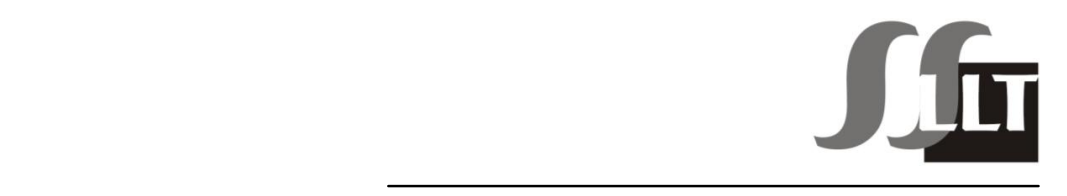

Studies in Second Language Learning and Teadhing

Department of English Studies, Faculty of Pedagogy and Fine Arts, Adam M ickiewicz University, Kalisz

SSLLT 3 (2). 321-324

http://www.ssllt.amu.edu.pl

\title{
Bookreviews
}

\section{The Strategy Factor in Successful Language Leaming}

\author{
Author: \\ Carol Griffiths \\ Publisher: \\ Multilingual Matters, 2013 \\ ISBN: \\ 978-1-84769-940-4 \\ Pages: \\ 220
}

The book by Carol Griffiths, titled The Strategy Factor in Successful Language Learning, is without doubt a valuable addition to research into the field of language learning strategies in the sense that, on the one hand, it may provide a source of inspiration for further studies, and, on the other, it may constitute a useful point of reference for second and foreign language teachers. The volume is divided into five main parts in which the author, having clarified the reasons for her own interest in this area, addresses key issues related to our understanding of learning strategies, the findings of her own research in this domain, as well as the ways in which strategy training can be incorporated into language pedagogy. The first part, "A Conceptual Perspective," touches upon a number of controversial issues connected with the field of language learning strategies, such as the terminology employed, the definition of the construct, factors impinging on the efficacy of strategy use, theoretical underpinnings, difficulties involved in the classification of strategies, as well as the challenges that are likely to be encountered in empirical investigations focusing on this area. In the second part, titled "A Quantitative Perspective," Carol Griffiths reports the results of her research endeavors with the 
aim of providing insights into such crucial issues as the relationship between the frequency and quantity of strategy use and successful language learning, the utility of specific strategy types, the impact of individual, situational and learning target related variables, the stability of strategy use over time, and the question whether modifications in the application of strategies lead to success as well as the issue as to whether strategies are the cause of progress in language learning or the effect of such progress. The third part, "A Qualitative Perspective," is based on data obtained from semi-structured interviews with ten learners, complemented with information about strategy use, individual variation and achievement, which allows the author to construct the individual profiles of these learners and offer further insights into the use of language learning strategies as well as factors impacting this use. The fourth part, entitled "A Pedagogical Perspective," is intended to demonstrate how the study of learning strategies can translate into classroom practice and does so by elucidating the place of strategic learning in theories of language teaching, providing a rationale for strategies-based instruction, giving an account of programs that can be used for this purpose, offering guidelines on how such training should be conducted and elucidating the impact of teachers' perceptions and learner variables in this respect. Finally, the fifth part, "Overview," highlights the main points brought up throughout the book and it is followed by appendices containing the data collection instruments used in the studies described earlier and a glossary including key terms related to the realm of language learning strategies.

My overall evaluation of the volume is very positive and I am deeply convinced that is it a much-needed, valuable addition to existing literature on language learning strategies. This is because, on the one hand, it attempts to impose some order on a field that is afflicted by numerous controversies, one of the most crucial of which is tied to the question whether the concept of strategy should be replaced with a more general construct such as self-regulation (Dörnyei, 2005), and, on the other, it does a superb job of reconciling theory and practice by demonstrating at every step the relevance of the issues discussed to language teachers. In fact, it is possible to point to a number of reasons why the book makes a worthwhile reading for wide audiences, not only scholars or researchers, but also practitioners as well as graduate and postgraduate students. For one thing, the author addresses some of the current controversies, related, among others, to the definition, distinctive features and characteristics of language learning strategies, offering reasonable solutions to at least some of them. Of particular interest, for example, is her attempt to define strategies according to their distinctive characteristics (Section 1.3. in Part 1), or to classify them according to the frequency of their application by more and less successful students (i.e., base, core, and plus strategies; Section 2.4. in Part 2). Second, in addition to offering a 
thorough overview of the key issues involved in the classification, description and strategy training, the author draws upon her own research to illustrate many of these points as well as providing directions for future empirical investigations in this area. Third, she manages to combine quite successfully the quantitative (Part 2) and qualitative (Part 3) paradigms, which is, by her own admission, a recognition of the fact that numbers and statistics cannot tell the whole story, and which allows her to gain much more insight into strategies that different learners use and the factors that may affect their employment in a particular situation. Fourth, she looks, if only somewhat superficially, into the dynamics of strategy use by tracing changes in this respect over time (Section 2.9 in Part 2 ), an area that has thus far been largely neglected by researchers. Fifth, she seeks to account for strategy use and in particular its relationship to attainment in terms of complex systems theories (e.g., Larsen-Freeman and Cameron, 2007; Section 2.10 in Part 2), although it would clearly be an overstatement to suggest that this is the theoretical perspective guiding her study of language learning strategies. Sixth, it is commendable that the volume offers a number of pedagogical implications for practitioners and that this is done in Part 4 on the basis of the quantitative and qualitative findings discussed in Parts 2 and 3. In a word, the book is in many ways original and it sheds new light on key issues involved in the study of language learning strategies.

Having said this, I would now like to focus on areas that, to my mind, can be viewed to some extent as weaknesses of the book. Even though I understand the intentions of the author when it comes to dividing the text into chapters and sections, reservations can be expressed about mixing theoretical considerations with research findings throughout the volume. One striking example concerns the discussion of variables impacting strategy selection, which is perhaps justified given their focus, but it is hard to see why the relevant theoretical issues (e.g., regarding aptitude, motivation, sex, affect, context) are discussed alongside the research findings in Parts 2, 3 and 4. It might be a better idea to include these in Part 1, which is intended as a theoretical background anyway and thus includes references to these factors, perhaps together with an overview of the results of studies of their influence on strategy use. Another problem is the fact that the theoretical issues relating to factors affecting strategy use are often discussed somewhat superficially, which is surely warranted given the main focus of the book but only as long as the discussion is confined to the role of a particular variable in shaping the application of learning strategies rather than attempting to provide a state-ofthe-art overview of research on a given variable. M ore specifically, there are problems with the interpretation of the motives given by learners, which is visible, for instance, in the following sentence on page 70: "Given that educational/employment goals might be considered extrinsic to the learner, something the 
student uses as an instrument to reach some further target, these findings might suggest that extrinsic/instrumental motivation types are more productive than the intrinsic/integrative types of motivation which drive those who want to travel or form friendships for their own personal satisfaction." The problem here is that the desire to get a good job or better education can be intrinsic as well if the learner feels that such goals are important to him or her, a comment which should alert us to the fact that instrumental and integrative motivational orientations can each be intrinsic or extrinsic, depending on whether the desire to learn comes from the learner, significant others or simply an attempt to ward off adverse consequences. Finally, although the author combines the quantitative and qualitative perspectives on the study of learning strategies, the research findings that she presents are still representative of what could be referred to as a macro perspective on strategy use, or such that aims to capture rather general, contextneutral patterns, rather than a micro perspective that taps into the application of strategies as they are employed in the performance of a specific task. Obviously, this can hardly be considered a weakness in the light of the fact that both of these approaches can be regarded as equally valuable, and this point is raised at this juncture only because combining these two approaches can be expected to offer the most valuable insights into strategy use.

These shortcomings notwithstanding, the book by Carol Griffiths is definitely worth reading as it considerably extends our knowledge about language learning strategies, it succeeds in addressing some of the most controversial issues, points to important directions for future research, and offers a number of feasible guidelines for practitioners. As a consequence, the book will be of relevance to wide audiences, ranging from theorists and researchers, through materials writers and teacher trainers, to classroom teachers and students enrolled in graduate and postgraduate courses.

Reviewed by

M irosław Pawlak

Adam Mickiewicz University in Poznań, Kalisz, Poland State School of Higher Professional Education, Konin, Poland pawlakmi@amiu.edu.pl

\section{References}

Dörnyei, Z (2005). The psychology of the language learner: Individual differences in second language acquisition. Mahwah, NJ: Lawrence Erlbaum.

Larsen-Freeman, D., \& Cameron, L. (2008). Complex systems and applied linguistics. Oxford: Oxford University Press. 